\title{
An Endogenously Produced Substance Essential for Growth Initiation of Pasteurella tularensis
}

\author{
By MIRIAM HALMANN AND J. MAGER \\ Cellular Biochemistry Research Unit, Department of Biochemistry, \\ The Hebrew University-Hadassah Medical School, Jerusalem, Israel
}

(Accepted for publication 21 June 1967)

\begin{abstract}
SUMMARY
Material produced by growing Pasteurella tularensis and required for the initiation of growth of $P$. tularensis from small inocula (growth-initiating substance, GIS) was purified by Sephadex gel filtration and ion-exchange resin chromatography. The purified material was characterized as an anionic compound of low molecular weight, heat-stable at neutral $\mathrm{pH}$ and in dilute alkali but destroyed by heating in dilute acid. Out of large variety of known nutrients tested, only iron salts and some iron-chelating compounds (sideramines) replaced partially GIS in supporting growth of different $P$. tularensis strains from small inocula. GIS formed complexes with iron and copper ions. The production of GIS by $P$. tularensis in a chemically defined medium was enhanced by added ornithine. Isotopic evidence established the role of ornithine as a biosynthetic precursor of GIS.
\end{abstract}

\section{INTRODUCTION}

Halmann, Benedict \& Mager (1967) showed that the growth of Pasteurella tularensis from small inocula was governed by a specific requirement for endogenously produced material termed 'growth-initiating substance' (GIS). The present paper is concerned with the purification of GIS, the determination of its characteristic properties and a study of its biosynthesis in a chemically defined medium.

\section{METHODS}

The various biological compounds used were acquired from the Sigma Chemical Co. (St Louis, Miss., U.S.A.). The Sephadex preparations were obtained from Pharmacia Fine Chemicals (Uppsala, Sweden). The other resins used were purchased from the Bio-Rad Laboratories (Richmond, California, U.S.A.). Radioactive compounds were obtained from the Radiochemical Centre, Amersham, Buckinghamshire, England.

Spectra were determined with a Beckman model DU spectrophotometer (Fullerton, California, U.S.A.) or with the Unicam SP 800 double-beam recording spectrophotometer (Cambridge, England), with silica cells of $\mathrm{I} \mathrm{cm}$. light path. Radioactivity was measured in a Tri-Carb model $314 \mathrm{~F}$ liquid scintillation counter (Packard Instrument Co., Downers Grove, Ill., U.S.A.), with Bray's scintillator solution (Bray, 1960). Sephadex gel filtration was done according to the procedure described by Flodin (I96r). Paper electrophoresis was done in a conventional apparatus under the conditions outlined below. The location of the GIS-active material on the electropherograms was 
facilitated by using ${ }^{14} \mathrm{C}$-labelled preparations of GIS (see below). The radioactive spots were detached with the aid of a Packard radiochromatogram scanner (model 720I) and eluted with distilled water. The eluted material was tested for GIS activity by determining the highest dilution capable of supporting growth on cysteine-blood agar of an inoculum containing 200 organisms of $P$. tularensis strain S \& D (see Halmann et al. 1967). The cultural procedures and other experimental details were as described by Halmann et al. (1967).

\section{RESULTS}

\section{Purification of growth initiating substance}

A $48 \mathrm{hr}$ cysteine broth culture of the Pasteurella tularensis strain S \& D was centrifuged for $20 \mathrm{~min}$. at $20,000 \mathrm{~g}$. The resulting bacterial deposit was discarded and the supernatant fluid concentrated in a flash evaporator at $40^{\circ}$ and then passed through a $14 \times 200 \mathrm{~mm}$ column Sephadex G-25. The column was then washed with distilled water and the effluent collected in 15 -drop portions, each fraction being assayed for GIS activity. Under these conditions GIS emerged from the column as a rather sharp peak, preceded by proteins and nucleic acids and followed by the bulk of amino acids, sugars and salts. The GIS-active samples were pooled and applied to a $9 \times 160 \mathrm{~mm}$ column of the anion-exchange resin Dowex 1 chloride. After rinsing the column with distilled water, the adsorbed material was eluted with stepwise increasing concentrations of $\mathrm{NaCl}$, successive Io $\mathrm{ml}$. samples of effluent being collected and tested for GIS activity. The elution profile of GIS is illustrated in Fig. I.

The combined GIS-active fractions were de-salted by filtration through a Sephadex G-Io column, treated batchwise with the cation-exchange resin Dowex 50 (hydrogen form) and then freeze-dried. The overall recovery of GIS in the final material amounted to $70-90 \%$ of the original GIS activity of the culture. In some instances, the fractionation on the Dowex I column was repeated with a $\mathrm{NaCl}$-gradient elution system. The specific activities of the purest GIS preparations obtained were in the range of 5 units/ $\mu \mathrm{g}$. dry weight (a unit is an amount of GIS enabling growth of a 200-organism inoculum of Pasturella tularensis strain S \& D on blood-cysteine agar; see Halmann et al. 1967). However, the degree of purity and homogeneity of these preparations could not be precisely evaluated by the criteria available.

From a brief survey of other microbial species, culture filtrates of a Rhizopus (see Halmann et al. I967) were found to offer a rich and convenient source of GIS. The substance was isolated in high yields by the procedure described above; its properties, including biological potency, proved to be identical to those of the material produced by the Pasteurella tularensis strains.

\section{Properties of growth-initiating substance}

The material isolated by the above procedure was readily soluble in water but insoluble in a variety of organic solvents (e.g. absolute ethanol, $n$-propanol, acetone, diethyl ether, chloroform, benzene). The activity of GIS was stable to autoclaving for $90 \mathrm{~min}$. at $120^{\circ}$ in neutral solution and in $0 . \mathrm{I} \mathrm{N}-\mathrm{NaOH}$. It withstood treatment for $2 \mathrm{hr}$ at about $25^{\circ}$ with $0.5 \mathrm{M}-\mathrm{H}_{2} \mathrm{O}_{2}, 0.3 \mathrm{M}$-nitrous acid and $0.05 \mathrm{M}-2$,4-dinitrofluorobenzene solution. Boiling GIS in $0.1 \mathrm{~N}-\mathrm{HCl}$ resulted in a rapid destruction of its activity. Occasionally, the unpredictable occurrence of a drastic loss of activity was noted in neutral aqueous solutions of GIS. Further work showed that this 'spon- 
taneous' inactivation of GIS was induced by its exposure to visible light. Moreover the photo-inactivation was found to be critically dependent upon the presence of traces of iron in the GIS solution and was completely prevented by treating the solution with the metal-chelating resin Chelex 100.

The low molecular weight of GIS was indicated by its diffusibility through cellophan membranes and its retention by Sephadex G-IO. The anionic properties of the substance were reflected in its adsorption on anion exchange resins (Dowex I, Amberlite IR-I20). In addition, a ${ }^{14} \mathrm{C}$-labelled preparation of GIS obtained by growing Pasteurella tularensis in the presence of $\left[{ }^{14} \mathrm{C}\right]$ ornithine (see below) exhibited anodic migration as a discrete radioactive spot, when subjected to electrophoresis on Whatman no. 3 MM paper in $0.025 \mathrm{M}$-barbital buffer ( $\mathrm{pH} \mathrm{8.6).}$

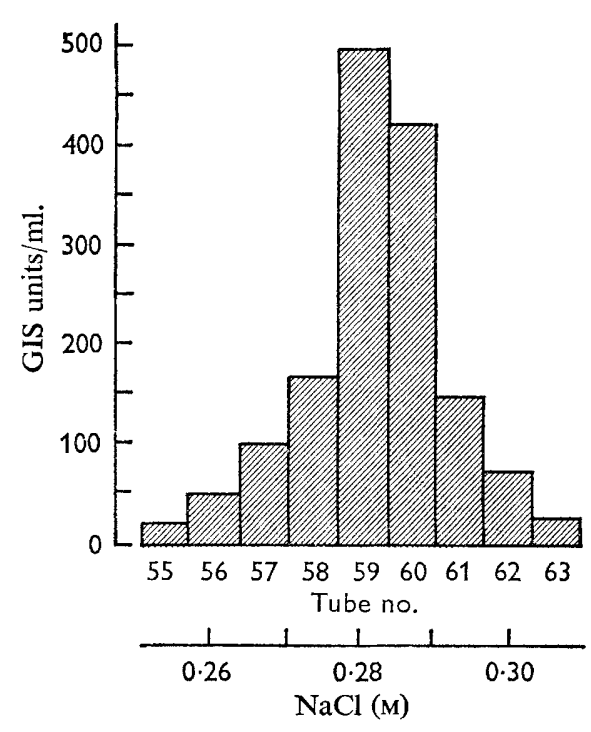

Fig. I
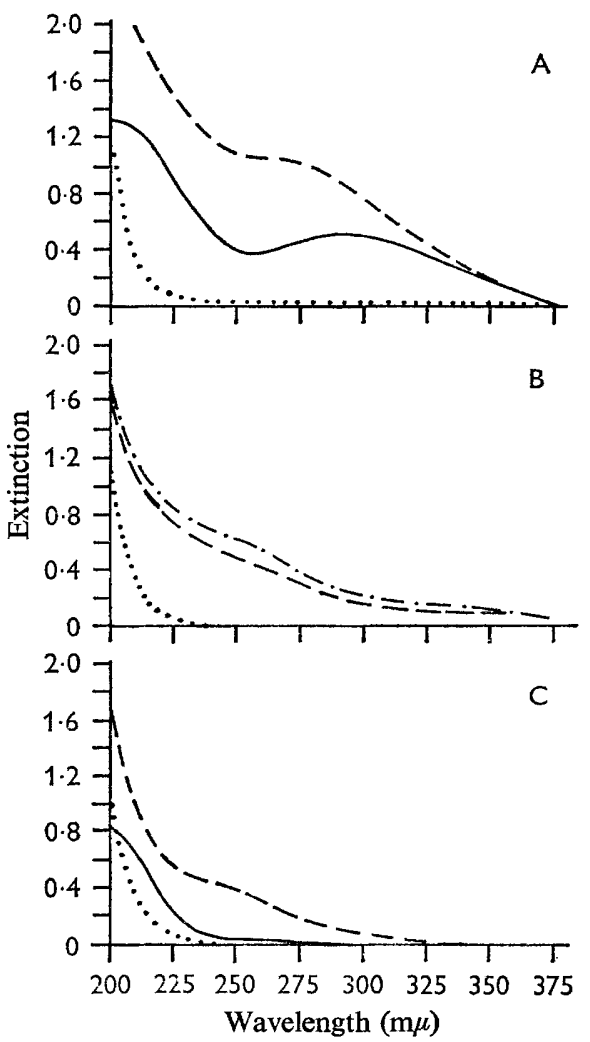

Fig. 2

Fig. I. Chromatography of growth-initiating substance GIS on a $9 \times 160 \mathrm{~mm}$ column of Dowex I-X8 (100-200 mesh, chloride form); elution profile. Each fraction was assayed for GIS activity as described by Halmann, Benedict \& Mager (1967). For unit definition see legend to Table I.

Fig. 2. Spectral changes attending formation of complexes between growth-initiating substance GIS and metals. The metals and GIS were dissolved in $1 \mathrm{ml}$. distilled water in the amounts specified below and the spectra were recorded with a Unicam SP 800 spectrophotometer, with distilled water in the reference cell. A: $\cdots$, GIS alone, $50 \mu \mathrm{g}$;,$- \mathrm{FeCl}_{3}$ alone, $0.25 \mu$ moles; - - -, GIS, $50 \mu \mathrm{g}$. $+\mathrm{FeCl}_{3}, 0.25 \mu$ moles. B: $\cdots$, GIS alone, $50 \mu \mathrm{g}$.; $\mathrm{FeSO}_{4}$ alone, $0.25 \mu$ moles; - - -, GIS, $50 \mu \mathrm{g}$. + FeSO, $0.25 \mu$ moles, 5 min after mixing; - . -, GIS $50 \mu \mathrm{g}$. $+\mathrm{FeSO}_{4}, 0.25 \mu$ moles, $60 \mathrm{~min}$. after mixing. C: $\cdots$, GIS alone, $50 \mu \mathrm{g}$; - - $\mathrm{CuSO}_{4}$ alone, $0.5 \mu$ moles; - - -, GIS, $50 \mu \mathrm{g}$. $+\mathrm{CuSO}_{4}, 0.5 \mu$ moles. 
GIS treated with the Dowex 50 cation exchanger and then titrated with $0 . \mathrm{I} N-\mathrm{KOH}$ with the aid of an automatic titrator (from Radiometer, Copenhagen, Denmark) yielded a $p K_{a}$ value of $5 . \mathrm{I}$ and a neutralization equivalent of about 280 . The latter value was reasonably near the maximum molecular weight of $274-276$, as determined with an Atlas PH-4 (Bremen, Germany) mass spectrometer. Details of these results will be presented elsewhere.

Qualitative tests for phosphate and sulphur were negative. Negative results were also obtained with ninhydrin, the Folin phenol reagent (Lowry, Rosebrough, Farr \& Randall, I95I) and the anthrone sugar reagent (Seifter, Dayton, Novic \& Montwyler, I950). Elemental analysis gave the values (corrected for $2 \%$ ash): $\mathrm{C}, 35 ; \mathrm{H}, 5.4 ; \mathrm{N}, 4.8$.

The most highly purified preparations of GIS showed no significant extinction in the range of about $250-800 \mathrm{~m} \mu$ and a progressively increasing end absorption in the shorter wavelengths (see Fig. 2).

\section{Metal-binding capacity of growth-initiating substance}

The iron-dependent photo-inactivation of GIS suggested a possible chemical interaction between these substances. The formation of different GIS complexes with both ferrous and ferric iron salts was revealed by their distinctive ultraviolet (u.v.) spectra (Fig. $2 \mathrm{~A}, \mathrm{~B}$ ). The spectrum of the GIS complex with $\mathrm{FeSO}_{4}$ exhibited a progressive change towards the stable ferric complex. This change was prevented by bubbling nitrogen through the $\mathrm{GIS}+\mathrm{FeSO}_{4}$ solution.

GIS also produced a complex with $\mathrm{Cu}^{2+}$, with a characteristic absorption in the ultraviolet region (Fig. 2 C). The rapid inactivation of GIS which occurred on heating it at pH I-2 manifested itself in the ultraviolet spectrum of the copper complex by a shift of extinction towards shorter wavelengths. The biologically inactive compound was further differentiated from native ${ }^{14} \mathrm{C}$-labelled GIS (see below) by the faster anodic migration of the inactive compound on paper electrophoresis in $0.025 \mathrm{M}$-acetate $(\mathrm{pH} 4 \cdot 7)$.

\section{Production of growth-initiating substance in a chemically defined medium}

Although the chemically defined medium of Traub, Mager \& Grossowicz (1955) supported profuse growth of different strains of Pasteurella tularensis, the amount of GIS produced in it amounted to about $\mathrm{I}-2 \%$ only of the average GIS yield obtained in the complex cysteine broth. Addition of Difco Proteose peptone $(0.5 \%, \mathrm{w} / \mathrm{v})$ or yeast extract $(0.25 \%, \mathrm{w} / \mathrm{v})$ to defined medium and then growing the organism permitted a 20 to Ioo-fold increase in GIS titre. About a fourfold purification of the material which increased GIS production (in terms of activity/dry weight) was achieved by filtering a $20 \%(\mathrm{w} / \mathrm{v})$ solution of the Difco yeast extract through a Sephadex G-25 column and treating the combined GIS-stimulatory fractions with Norit A charcoal. The purified material exhibited no appreciable extinction over the spectral range 220-700 $\mathrm{m} \mu$, and yielded with the ninhydrin reagent (Yemm \& Cocking, I955) approximately $30 \%$ of the colour obtained with the equivalent amount of untreated yeast extract. The activity of the preparation in promoting GIS production in the defined medium was not appreciably decreased by autoclaving at $15 \mathrm{lb}$./sq.in. in the presence of $\mathrm{N}-\mathrm{NaOH}$ or $6 \mathrm{~N}-\mathrm{HCl}$ for as long as $6 \mathrm{hr}$.

Subsequent work showed that the active component of the yeast extract could be replaced by ornithine. Addition of glutamate resulted in a further enhancement of 
GIS production, but the magnitude of this effect varied considerably in different experiments. Citrulline was less active than ornithine; arginine produced only a very limited degree of enhancement of GIS production (Table I).

\section{Table I. Effect of added glutamate and basic amino acids on production of growth-initiating substance by Pasteurella tularensis strain $S \& D$}

The composition of the chemically defined medium was as described by Traub, Mager \& Grossowicz (1955). The GIS titres were determined after $48 \mathrm{hr}$ incubation at $37^{\circ}$ by adding serial dilutions of the sterile culture filtrate to cysteine blood agar (CB). One unit of GIS is defined as the quantity required for growth of a 200-organism inoculum of $P$. tularensis strain S \& D on CB agar after $48 \mathrm{hr}$ incubation at $37^{\circ}$ (see Halmann, et. al, 1967).

$\begin{array}{lc}\text { Additions to the defined medium }(\mu \mathrm{g} . / \mathrm{ml} .) & \text { GIS (units } / \mathrm{ml} \text {.) } \\ \text { None } & 3 \\ \text { L-Glutamate, I000 } & 5 \\ \text { Yeast extract, 2500 } & 60 \\ \text { Purified fraction of yeast extract, 600 } & 60 \\ \text { L-Ornithine, 30+ L-glutamate, 1000 } & 30 \\ \text { L-Ornithine, I00+ L-glutamate, I000 } & 90 \\ \text { L-Ornithine I00 } & 20 \\ \text { L-Citrulline, 30 } & 30 \\ \text { L-Citrulline, 100 + L-glutamate, I000 } & 30 \\ \text { L-Arginine, I00+ glutamate, I000 } & 8 \\ \text { L-Arginine, 3000 + L-glutamate, 1000 } & 8\end{array}$

Table 2. Incorporation of various ${ }^{14} \mathrm{C}$-compounds into growthinitiating substances GIS

The ${ }^{14} \mathrm{C}$-labelled compounds were added to $3 \mathrm{ml}$. of defined medium of Traub, Mager \& Grossowicz (I955) at a final specific activity of about $5 \mu \mathrm{c} / \mu$ mole. After incubation at $37^{\circ}$ for $48 \mathrm{hr}$ the organisms were removed by centrifugation. To the supernatant fluid 2000 units GIS were added as carrier and re-isolated by chromatography on a Dowex I column. Under these conditions all the compounds tested separated well from GIS. The corresponding fractions were tested for GIS activity and for radioactivity. The values for GIS-bound radioactivity were corrected for quenching and for \% recovery of GIS which varied in different experiments from 80 to $100 \%$. In calculating the radioactivities of DL-amino acids, the L-isomer was assumed to be the only biologically active form. Other conditions were as in Fig. $\mathrm{I}$.

Compound tested

$\left[2{ }^{x}\right.$ C]DL-Ornithine

$\left[5^{-14} \mathrm{C}\right] \mathrm{DL}$-Ornithine

$\left[{ }^{14} \mathrm{C}\right] \mathrm{L}$-Lysine, uniformly-labelled

$\left[{ }^{14} \mathrm{C}\right] \mathrm{L}$-Valine, uniformly labelled

$\left[{ }^{14} \mathrm{C}\right] \mathrm{L}-$ Glutamate, uniformly-labelled

$\left[{ }^{14} \mathrm{C}\right] \mathrm{D}-\mathrm{Glucose}$, uniformly-labelled

$\left[{ }^{14} \mathrm{C}\right]$ Acetate

Amount of radio-
activity supplied
in the medium
(counts/min.)
$(A)$
20,000
36,000
130,000
79,000
57,000
680,000
650,000

Amount of radioactivity recovered radioactivity in the GIS fraction incorporated (counts/min.)

13,890
23,500
0
0
0
2,100
1,450
$(B \times 100 / A)$

\section{Incorporation of labelled precursors into growth-initiating substance}

The above data pointed to a possible role of ornithine as a biosynthetic precursor of GIS. This possibility was tested by growing Pasteurella tularensis strain S \& D in the defined medium supplemented with ${ }^{14} \mathrm{C}$-labelled ornithine and isolating GIS by 
the chromatographic procedure described above (see legend to Table 2). The distribution of the radioactivity closely paralleled the fractionation profile of GIS. When the isolated ${ }^{14} \mathrm{C}$-labelled GIS was subjected to paper electrophoresis in barbital buffer (pH 8.6), the radioactivity and the biological activity migrated together. Regardless of whether the isotopic label was in the $\alpha$ or $\delta$ position of ornithine, the percentage of radioactivity incorporated into GIS was practically the same (Table 2 ). It appeared likely, therefore, that ornithine was incorporated as a whole into the molecule of GIS.

Several other ${ }^{14} \mathrm{C}$-labelled amino acids (e.g. glutamate, lysine, valine) showed no significant incorporation into GIS. Substantial incorporation was obtained with $\left[\mathrm{I}-{ }^{14} \mathrm{C}\right]$ acetate and uniformly labelled $\left[{ }^{14} \mathrm{C}\right]$ glucose (Table 2 ). However, the data recorded in Table 2 do not represent true incorporation yields of the various compounds tested (in terms of relative specific activities), because of the disparity in the extent of dilution of their isotope contents by the respective endogenous pools.

\section{Specificity of growth-initiating substance; relationship to sideramines}

A large number of growth factors, including vitamins, coenzymes and other known essential metabolites, did not replace GIS in promoting growth from small inocula of Pasteurella tularensis on blood cysteine agar. The substances tested and found inert (at $\mathrm{mg}$./ $100 \mathrm{ml}$. blood-cysteine agar) were: acetic acid, Io; $\mathrm{N}$-acetyl glucosamine, Io; $\mathrm{NaHCO}_{3}, 20$; catalase (beef liver, crystalline), 5; citric acid (sodium salt), 10; cobamide coenzyme (dimethyl benzimidazole derivative), $0.0 \mathrm{I}$; coenzyme $\mathrm{A}$ ( $70 \%$ pure), 2 ; cyanocobalamine, 0.01 ; $m$-diaminopimelic acid, 5 ; D-galactosamine, IO; D-glucosamine, I0; L-glutamine, I0; flavin-adenine dinucleotide, 1.5 ; flavin-adenine mononucleotide, I; haemin, $0 . \mathrm{I}$; $m$-inositol, Io; mixture of nucleosides (adenosine + guanosine + uridine + cytidine + thymidine), $2 \mathrm{mg}$. each; mixture of nucleoside -5 monophosphates (AMP + GMP + UMP + CMP + TMP), 2 mg. each; nicotinamideadenine dinucleotide, I; nicotinamide-adenine dinucleotide phosphate, I; $\alpha$-oxoglutaric acid (sodium salt), Io; pyridoxal, 2; pyridoxal phosphate, 2; thioctic acid (sodium salt), I; thioctic acid amide, I; thiamine pyrophosphate, I; ubiquinone, 0.5 .

The iron-complexing ability of GIS and the precursor role of ornithine in its biosynthesis suggested a possible relation of GIS to a group of compounds of microbial origin known as sideramines, which are characterized by their potent iron-chelating capacity inherent in the repeating hydroxylamino groups, the latter being essential components of their structural pattern, most commonly derived from $\delta$ - $N$-hydroxyornithine (Neilands, 1957; Zaehner et al. 1963; Emery, 1965, 1966).

The chemical dissimilarity between GIS and the sideramines was shown by the negative reaction of GIS for hydroxamic acid when tested by the method of Csáky ( 1948 ), either directly or following heating with $\mathrm{N}-\mathrm{HCl}$. A certain degree of overlapping in their biological activities was indicated by the finding that some of the sideramines examined (ferrichrome, ferrioxamine B, ferrichrysin) were capable of decreasing by a factor of 100-1000 the critical size of inoculum for growth of several strains of Pasteurella tularensis in the absence of added GIS (Table 3). However, the minimal inocula required for growth initiation were still about $\mathrm{ro}^{2}-\mathrm{IO}^{6}$ times larger with the sideramines than with GIS. Furthermore, the effective dose of the sideramines was in the range of $10-20 \mu \mathrm{g} . / \mathrm{ml}$. culture medium, i.e. nearly 500-1000 times higher than that of GIS. On the other hand, GIS in amounts as high as $100 \mu \mathrm{g} / \mathrm{ml}$. showed no growth-factor activity for Arthrobacter JG-9, whose growth has been shown by 
Burnham \& Neilands (I96I) to be dependent upon ferrichrome or other sideramines. With the majority of strains of $P$. tularensis tested the effect of sideramines was duplicated by inorganic iron salts (ferrous and ferric); $\mathrm{FeSO}_{4}$ was reported by Tresselt $\&$ Ward (I964) to support under certain conditions colonial growth of the 'Schu' strain of $P$. tularensis.

\section{Table 3. Effect of inorganic iron and some sideramines on the critical inoculum size of some strains of Pasteurella tularensis}

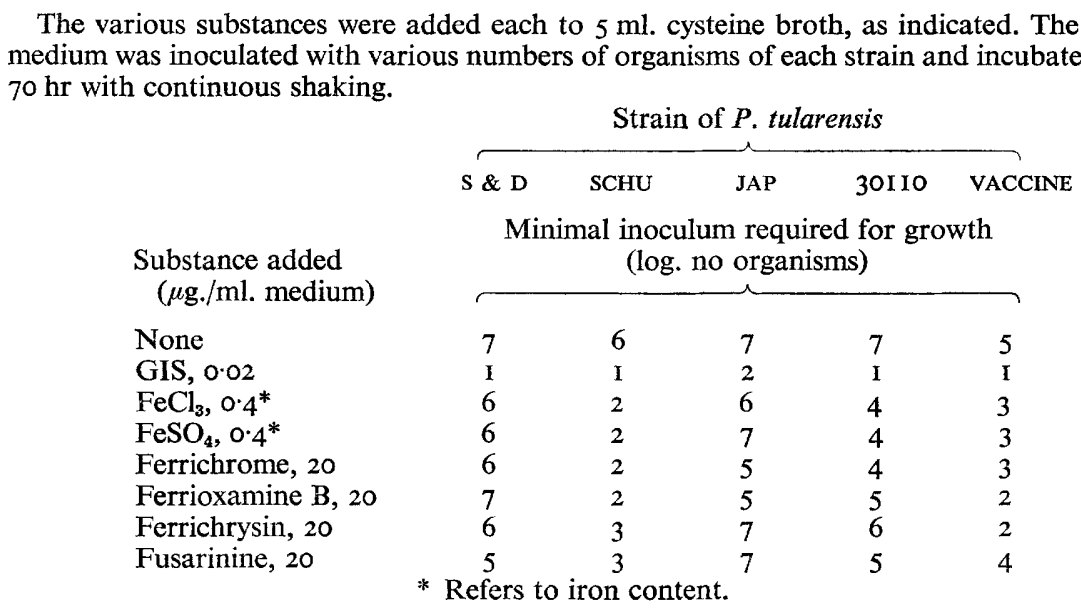

\section{DISCUSSION}

A variety of conventional peptone-containing or chemically defined media have been reported as capable of supporting colonial growth of different strains of Pasteurella tularensis (Snyder, Engley, Penfield \& Creasey, I964; Downs, Corriell, Chapman \& Klauber, 1947; Won, 1958; Nagle, Anderson \& Gary, I960; Hood, 196I; Gaspar, Tresselt \& Ward, 1961). These claims are at variance with our findings about the apparently novel and specific nature of the endogenously produced growth initiating substance GIS required for initiating growth of $P$. tularensis from small inocula. The discrepancy cannot be accounted for solely by strain differences, i.e. disparities in the degree of dependence of different strains on the exogenous supply of GIS, since some of the strains used in the studies quoted above and in the present investigation were of identical origin. It appears that some subtle differences in the cultural conditions used, perhaps of a physical or physico-chemical nature, may be of greater importance than hitherto recognized in determining the inoculum-dependent growth characteristics and the requirement for GIS. The metal-binding property of GIS, as well as its partial replacement by iron salts and some sideramines point to a possible role of GIS in the trace-metal metabolism of $P$. tularensis.

The authors express their appreciation to Drs J. B. Neilands, T. Emery and $H$. Zaehner for generously providing pure samples of various sideramines. They are indebted to Dr N. Danielli of the Weizmann Institute of Science for his help with the mass spectrometric analysis. The skilful technical assistance of Miss Tamar Sari is gratefully acknowledged. 
This paper is part of a Ph.D. thesis to be submitted by Mrs M. Halmann to the Hebrew University, Jerusalem.

\section{REFERENCES}

Bray, G. A. (1960). A simple efficient liquid scintillator for counting aqueous solutions in a liquid scintillation counter. Analyt. Biochem. $\mathbf{x}, 279$.

Burnham, B. F. \& Neilands, J. B. (196I). Studies on the metabolic function of the ferrichrome compounds. J. biol. Chem. 236, 554.

CsÁky, T. Z. (1948). On the estimation of bound hydroxylamine in biological materials. Acta chem. scand. 2, 450.

Downs, C. M., Correll, L. L., Chapmann, S. S. \& Klauber, A. (1947). The cultivation of Bacterium tularense in embryonated eggs. J. Bact. 53, 89.

EMERY, T. (1965). Isolation, characterization and properties of fusarinine, a hydroxamic acid derivative of ornithine. Biochemistry 4, 1410.

EMERY, T. (1966). Initial steps in the biosynthesis of ferrichrome. Incorporation of $\delta$ - $N$-hydroxyornithine and $\delta$ - $N$-acetyl $\delta$ - $N$-hydroxyornithine. Biochemistry 5, 3694 .

FLodin, P. (196I). Methodological aspects of gel filtration with special reference to desalting operations. J. Chromatog. 5, 103.

Gaspar, A. J., Tresselt, H. B. \& WARD, M. K. (1961). New solid medium for enhanced growth of Pasteurella tularensis. J. Bact. 82, 564.

Halmann, M., Benedict, M. \& MAGER, J. (1967). Nutritional requirements of Pasteurella tularensis for growth from small inocula. J. gen. Microbiol. 49, 45I.

Hood, A. M. (1961). A growth medium without blood cells for Pasteurella tularensis. J. gen. Microbiol. 26,45 .

Lowry, O. H., Rosebrough, N. J., Farr, A. L. \& Randall, R. J. (I95I). Protein measurement with the Folin phenol reagent. J. biol. Chem. 193, 265.

NAGLe, S. C. Jun., ANDERson, R. E. \& GARY, N. D.(1960). Chemically defined medium for the growth of Pasteurella tularensis. J. Bact. 79, 566.

NeILANDS, J. B. (1957). Some aspects of microbial iron metabolism. Bact. Rev. 2I, Ior.

Seifter, S., Dayton, S., Novic, B. \& MonTwYler, E. (1950). The estimation of glycogen with the antrone reagent. Archs Biochem. 25, 191.

Snyder, T. L., Engley, F. B. Jun., Penfield, R. A. \& Creasy, J. C. (I946). A dilution plate counting method for certain strains of Bacterium tularense. J. Bact. 52, $24 \mathrm{I}$.

Traub, A., Mager, J. \& Grossowicz, N. (I955). Studies on the nutrition of Pasteurella tularensis. J. Bact. 70, 60.

Tresselt, H. B. \& WARD, M. K. (1964). Blood-free medium for the rapid growth of Pastelirella tularensis. Appl. Microbiol. 12, 504.

Won, W. D. (1958). A medium for the cultivation of Pasteurella tularensis. J. Bact. 75, 237.

Yемм, E. W. \& Cocking, E. C. (1955). The determination of amino-acids with ninhydrin. Analyst 80, 209.

Zaehner, H., Keller-Schierlein, W., Huetter, R., Hess-Leisinger, K. \& Deer, A. (I963). Stoffwechselprodukte von Mikroorganismen. Arch. Mikrobiol. 45, I 19. 